\title{
PELAYANAN KESEHATAN PADA KLINIK PRATAMA RAWAT INAP \\ (Studi Tentang Penerapan Peraturan Menteri Kesehatan RI. Nomor 028/ Menkes/ Per///2011 Tentang Klinik Di Kabupaten Cilacap)
}

\author{
Listyorini \\ Magister Ilmu Hukum Fakultas Hukum Universitas Jenderal Soedirman
}

\begin{abstract}
Abstrak
Pelayanan kesehatan pada Klinik Pratama Rawat Inap dan faktor-faktor yang mempengaruhi terjadinya pelanggaran serta penerapan sanksi terhadap Klinik Pratama Rawat Inap di Kabupaten Cilacap dalam memberikan pelayanan kesehatan sesuai dengan Permenkes RI Nomor 028/Menkes/Per///2011 Tentang Klinik. Penelitian menggunakan pendekatan yuridis sosiologis. Penelitian menggunakan data primer bersumber dari Kepala Bidang Pelayanan Kesehatan dan Kefarmasian Dinas Kesehatan Kabupaten Cilacap, Kepala Klinik Pratama Rawat Inap, Tenaga Kesehatan pemberi pelayanan kesehatan pada Klinik Pratama Rawat Inap dan masyarakat yaang menggunakan jasa pelayanan Klinik Pratama Rawat Inap. Pelayanan kesehatan yang diselenggarakan oleh Klinik Pratama Rawat Inap belum sepenuhnya sesuai dengan yang diatur dalam Permenkes RI Nomor 028/Menkes/Per/I/2011 tentang Klinik. Faktor terjadinya pelanggaran yaitu: 1) Ketidaktahuan pengelola tentang perizinan radiologi. 2) Keterbatasan SDM (dokter) yang berdomisili dekat dengan Klinik. 3) apoteker pengelola tidak seimbang dengan jumlah apoteker yang ada. 4) Pengawasan tidak berjalan dengan baik. 5) Sanksi belum memiliki daya paksa karena hanya bersifat saran dan teguran lisan maupun tertulis. 6) Pemerintah Daerah belum membuat peraturan daerah tentang klinik.
\end{abstract}

Kata Kunci : Klinik, Pelayanan Kesehatan, Pelanggaran

\begin{abstract}
Abtract
Health services at the clinic Pratama Hospitalization and the factors that affect the violations as well as the application of sanctions against Clinics Pratama Hospitalization in Cilacap Regency in providing health services in accordance with Permenkes RI Number 028/Menkes/Per/I/2011 About the clinic. Juridical sociological approach uses research. Research using primary data sourced from the head of the Ministry of health and District Health Service Kefarmasian Cilacap, head of Clinic Pratama Inpatient health care personnel, health care givers on Inpatient Clinic Pratama and community Clinics services using yaang Pratama hospitalization. Organized by the health services Clinic Pratama Hospitalization is not fully in accordance with that set forth in Permenkes RI Number 028/Menkes/Per/l/2011 about the clinic. Factors of occurrence of offences, namely: 1) Ignorance about licensing Manager Radiology. 2) Limitations of human resources (doctor), a company based near to the clinic. 3) pharmacist-Manager was disproportionate to the number of existing pharmacies.
\end{abstract}

\section{Pendahuluan}

Upaya peningkatan kualitas hidup manusia di bidang kesehatan, merupakan suatu usaha yang sangat luas dan menyeluruh, usaha tersebut meliputi peningkatan kesehatan masyarakat baik fisik maupun non fisik. Sistem Kesehatan Nasional me- nyebutkan bahwa kesehatan menyangkut semua segi kehidupan yang ruang lingkup dan jangkauannya sangat luas dan kompleks. Hal ini sesuai dengan pengertian kesehatan yang diberikan oleh dunia Internasional sebagai berikut: $A$ state of complete physical, mental, and social, well being and 
51 Jurnal Idea Hukum

Vol. 1 No. 1 Edisi Maret 2015

Magister Hukum Fakultas Hukum Universitas Jenderal Soedirman

not merely the absence of deseaseor infirmity. ${ }^{1}$

Peraturan Menteri Kesehatan Republik Indonesia No. 028/Menkes/Per/l/2011 Tentang Klinik Pasal 1 ayat (1) menyebutkan:

Klinik adalah fasilitas pelayanan kesehatan yang menyelenggarakan pelayanan kesehatan perorangan yang menyediakan pelayanan medis dasar dan /atau spesialistik, diselenggarakan oleh lebih dari satu jenis tenaga kesehatan dan dipimpin oleh seorang tenaga medis.

Pendirian klinik diatur dalam Pasal 6 Peraturan Menteri Kesehatan Republik Indonesia No. 028/Menkes/Per///2011 Tentang Klinik yaitu klinik harus memenuhi persyaratan lokasi, bangunan dan ruangan, prasarana, peralatan, dan ketenagaan. Terlindunginya pasien untuk mendapatkan pelayanan kesehatan tidak hanya didasarkan pada terpenuhinya persyaratan tersebut, namun justru proses pelayanan kesehatan yang dalam konteks penelitian ini adalah pelayanan kesehatan rawat inap. Pelayanan pada pasien rawat inap di klinik diatur dalam Pasal 22 sebagai berikut.

(1) Klinik yang menyelenggarakan pelayanan rawat inap harus menyediakan:

a. ruang rawat inap yang memenuhi persyaratan;

b. tempat tidur pasien minimal 5 (lima) dan maksimal 10 (sepuluh);

c. tenaga medis dan keperawatan yang sesuai jumlah dan kualifikasinya;

d. tenaga gizi, tenaga analis kesehatan, tenaga kefarmasian dan tenaga kesehatan dan/atau tenaga non kesehatan lain sesuai kebutuhan;

e. dapur gizi;

Hermien Hadiati Koeswadji, 1998, Hukum Kedokteran, (Studi Tentang Hubungan Hukum Dalam Mana Dokter Sebagai Salah Satu Pihak), Citra Aditya Bakti, Bandung, hlm. 17. f. pelayanan laboratorium Klinik Pratama.

(2) Pelayanan rawat inap hanya dapat dilakukan maksimal selama 5 (lima) hari.

Peraturan Menteri Kesehatan Republik Indonesia No. 028/Menkes/ Per/l/2011 Tentang Klinik. diantaranya mengatur tentang pelayanan medik dasar dengan rawat inap, hal tersebut masih menimbulkan kerancuan dalam pelaksanaan di lapangan. Klinik Pratama Rawat Inap di Kabupaten Cilacap berkembang cukup pesat. Sampai dengan tahun 2012 telah dikeluarkan izin pendirian klinik sebanyak 24 klinik. ${ }^{2}$

\section{Perumusan Masalah}

Bagaimana pelayanan kesehatan pada Klinik Pratama Rawat Inap dan faktorfaktor yang mempengaruhi terjadinya pelanggaran Permenkes RI Nomor 028/Menkes/Per/l/2011 Tentang Klinik.

\section{Metode Penelitian}

Penelitian ini merupakan penelitian kualitatif dengan pendekatan yuridis sosiologis yaitu merupakan gabungan antara penelitian lapangan yang menggunakan data sekunder berupa peraturan perundangundangan bidang kesehatan, dan penelitian kepustakaan serta data primer berupa observasi lapangan dan wawancara dengan informan. ${ }^{3}$ Informan ditentukan dengan teknik snowball, yaitu cara pemilihan informan yang didasarkan atas petunjuk informan kunci.

\section{Pembahasan}

Pasal 21 Peraturan Menteri Kesehatan Republik Indonesia Nomor 028/Menkes/Per/I/2011 Tentang Klinik disebutkan:

(1) Untuk mendirikan dan menyelenggarakan klinik harus mendapat izin dari pemerintah daerah kabupaten/

Dinas Kesehatan Kabupaten Cilacap tahun 2012

Angkasa. 1993. Prisonisasi dan Permasalahannya terhadap Pembinaan Narapidana. Tesis. Universitas Diponegoro. Semarang. hlm 19. 
kota setelah mendapatkan rekomendasi dari dinas kesehatan kabupaten/ kota setempat.

(2) Dinas kesehatan kabupaten/kota mengeluarkan rekomendasi sebagaimana dimaksud pada ayat (1) setelah klinik memenuhi ketentuan persyaratan klinik dalam Peraturan ini.

(3) Permohonan izin klinik diajukan dengan melampirkan: a) surat rekomendasi dari dinas kesehatan setempat; b) salinan/fotokopi pendirian badan usaha kecuali untuk kepemilikan perorangan; c) identitas lengkap pemohon; d) surat keterangan persetujuan lokasi dari pemerintah daerah setempat; e) bukti hak kepemilikan atau penggunaan tanah atau izin penggunaan bangunan untuk penyelenggaraan kegiatan bagi milik pribadi atau surat kontrak minimal selama 5 (lima) tahun bagi yang menyewa bangunan untuk penyelenggaraan kegiatan; f) dokumen Upaya Pengelolaan Lingkungan (UKL) dan Upaya Pemantauan Lingkungan (UPL); g) profil klinik yang akan didirikan meliputi struktur organisasi kepengurusan, tenaga kesehatan, sarana dan prasarana, dan peralatan serta pelayanan yang diberikan; dan h) persyaratan administrasi lain sesuai dengan ketentuan peraturan perundang-undangan.

(4) Izin klinik sebagaimana dimaksud pada ayat (1) diberikan untuk jangka waktu 5 (lima) tahun dan dapat diperpanjang dengan mengajukan permohonan perpanjangan 6 (enam) bulan sebelum habis masa berlaku izinnya.

(5) Pemerintah daerah kabupaten/kota dalam waktu 3 (tiga) bulan sejak permohonan diterima harus menetapkan menerima atau menolak permohonan izin atau permohonan perpanjangan izin.

(6) Permohonan yang tidak memenuhi syarat ditolak oleh pemerintah daerah kabupaten/kota dengan memberikan alasan penolakannya secara tertulis.

Berdasarkan pada hasil wawancara dengan informan diperoleh informasi, bahwa proses pendirian Klinik Pratama Rawat Inap yang dilakukan melalui Dinas Kesehatan. Pemilik Klinik Pratama Rawat Inap di Kabu- paten Cilacap bersifat badan usaha. Persyaratan administrasi maupun bangunan disiapkan sebagai persyaratan agar dapat memberikan pelayanan kesehatan yang standar sesuai dengan kewenangan Klinik Pratama Rawat Inap.

Kendala yang dihadapi dalam pendirian Klinik Pratama Rawat Inap lebih bersifat internal seperti kesulitan dalam mendapatkan SDM yang sesuai persyaratan Kegiatan pelayanan kesehatan kepada pasien yang diberikan oleh Klinik Pratama Rawat Inap sudah sesuai dengan kewenangan sebagaimana diatur dalam Peraturan Menteri Kesehatan Republik Indonesia Nomor 028/Menkes/Per/l/2011 Tentang Klinik pada Pasal 4 sebagai berikut.

(1)Klinik menyelenggarakan pelayanan kesehatan yang bersifat promotif, preventif, kuratif dan rehabilitatif.

(2)Pelayanan kesehatan sebagaimana dimaksud pada ayat (1) dilaksanakan dalam bentuk rawat jalan, one day care, rawat inap dan/atau home care.

(3) Klinik yang menyelenggarakan pelayanan kesehatan 24 (dua puluh empat) jam harus menyediakan dokter serta tenaga kesehatan lain sesuai kebutuhan yang setiap saat berada di tempat.

Berdasarkan temuan peneliti di Klinik Pratama Rawat Inap, dokter berada di Klinik Pratama Rawat Inap hanya pada saat melakukan pemeriksaan. Dokter tidak selalu ada di Klinik Pratama Rawat Inap, sehingga tidak selalu siap jika dibutuhkan. Tenaga kesehatan yang selalu siap 24 jam hanya tenaga perawat. Hal ini menunjukkan telah terjadi pelanggaran terhadap ketentuan yang diatur dalam Pasal 4 ayat (3) Peraturan Menteri Kesehatan Republik Indonesia Nomor 028/ Menkes/Per/l/2011 Tentang Klinik.

Pelayanan kesehatan bersifat kuratif dan rehabilitatif. Adapun penyakit yang ditangani oleh Klinik Pratama Rawat Inap antara lain diare, Typhoid fever, Ispa dan sebagai- 
53 Jurnal Idea Hukum

Vol. 1 No. 1 Edisi Maret 2015

Magister Hukum Fakultas Hukum Universitas Jenderal Soedirman

nya yang masih menjadi kewenangan Klinik Pratama Rawat Inap.

Letak atau alamat operasional Klinik Pratama Rawat Inap tidak tersebar merata sehingga ada yang letaknya berdekatan dengan rumah sakit. Klinik Pratama Rawat Inap yang pemiliknya dokter tidak memperkerjakan dokter lain, dokter yang berstatus PNS tidak mempekerjakan dokter lain terapi dilakukan melalui telpon yang dinstruksikan kepada perawat. Klinik Pratama Rawat Inap yang pemiliknya bukan dokter mepekerjakan dokter dengan jangkauan yang relatif jauh dari domisili dokter penanggungjawab ataupun dokter sebagai pelaksana. Masyarakat masih banyak yang memanfaatkan pelayanan kesehatan di Klinik Pratama Rawat Inap. Alasan yang diberikan oleh pasien adalah karena faktor dekat dengan rumah dan karena tergesa-gesa agar pasien segera mendapatkan pengobatan.

Ketentuan tentang persyaratan lokasi klinik sebagaimana diatur dalam Pasal 7 ayat (2) menentukan adanya pengaturan persebaran klinik yang diselenggarakan masyarakat di wilayahnya dengan memperhatikan kebutuhan pelayanan berdasarkan rasio jumlah penduduk. Peraturan perundang-undangan (peraturan daerah) tentang persebaran klinik sampai saat penelitian dilakukan belum ada. Hal ini menyebabkan Klinik Pratama Rawat Inap tidak tersebar merata. Beberapa Klinik Pratama Rawat Inap letaknya berdekatan dengan rumah sakit dengan jangkauan yang relatif jauh dari domisili dokter penanggungjawab ataupun dokter sebagai pelaksana, merupakan salah satu faktor yang dapat mempengaruhi pelayanan kesehatan tidak memenuhi standar.

Sesuai dengan yang diatur dalam Pasal 8 ayat (1) Peraturan Menteri Kesehatan Republik Indonesia Nomor 028/Menkes/Per/l/2011 Tentang Klinik bahwa klinik diselenggarakan pada bangunan yang permanen dan tidak bergabung dengan tempat tinggal atau unit kerja lainnya. Berdasarkan hasil temuan oleh Dinas Kesehatan, masih ada Klinik Pratama Rawat Inap yang bergabung dengan rumah tinggal. Dinas Kesehatan telah memberikan teguran agar memisahkan tempat tinggal dengan bangunan klinik. Pasal 12 Peraturan Menteri Kesehatan Republik Indonesia Nomor 028/Menkes/Per/ I/2011 Tentang Klinik disebutkan:

Peralatan medis yang digunakan di klinik harus diuji dan dikalibrasi secara berkala oleh Balai Pengamanan Fasilitas Kesehatan dan/atau institusi penguji dan pengkalibrasi yang berwenang.

Selanjutnya pada Pasal 13 Peraturan Men-teri Kesehatan Republik Indonesia Nomor 028/Menkes/Per/l/2011 Tentang Klinik dise-butkan:

Peralatan medis yang menggunakan radiasi pengion harus mendapatkan izin sesuai ketentuan peraturan perundang-undangan.

Hasil temuan Dinas Kesehatan diketahui masih adanya Klinik Pratama Rawat Inap yang menggunakan alat radiologi belum memilik izin. Hal ini telah melanggar Peraturan Menteri Kesehatan Republik Indonesia Nomor 028/Menkes/Per///2011 Tentang Klinik pasal 12 dan 13.

Pengawasan oleh Dinas Kesehatan terhadap Klinik Pratama Rawat Inap menemukan belum adanya apoteker sebagai penanggung jawab ruang farmasi jelas melanggar ketentuan yang diatur dalam Pasal 22 Peraturan Menteri Kesehatan Republik Indonesia Nomor 028/Menkes/Per/l/2011 Tentang Klinik yang menegaskan bahwa

(1) Klinik yang menyelenggarakan pelayanan rawat inap harus menyediakan: a) ruang rawat inap yang memenuhi persyaratan; b) tempat tidur pasien minimal 5 (lima) dan maksimal 10 (sepuluh); c) tenaga medis dan keperawatan yang sesuai jumlah dan kualifikasinya; d) tenaga gizi, tenaga analis kesehatan, tenaga kefarmasian dan tenaga kesehatan dan/atau tenaga 
non kesehatan lain sesuai kebutuhan; e) dapur gizi; f) pelayanan laboratorium Klinik Pratama.

(2) Pelayanan rawat inap hanya dapat dilakukan maksimal selama 5 (lima) hari.

\section{Pasal 24}

(1) Klinik menyelenggarakan pengelolaan dan pelayanan kefarmasian melalui ruang farmasi yang dilaksanakan oleh apoteker yang memiliki kompetensi dan kewenangan untuk itu.

(2) Apabila klinik berada di daerah yang tidak terdapat Apoteker sebagaimana dimaksud pada ayat (1), pelayanan kefarmasian dapatdilaksanakan oleh tenaga teknis kefarmasian sesuai dengan ketentuan peraturan perundangundangan.

(3) Ruang farmasi sebagaimana dimaksud pada ayat (1) hanya dapat melayani resep dari tenaga medis yang bekerja di klinik yang bersangkutan.

Pasal 22 ayat (2) Peraturan Menteri Kesehatan Republik Indonesia Nomor 028/ Menkes/Per/l/2011 Tentang Klinik menentukan tentang pelayanan rawat inap hanya dapat dilakukan maksimal selama 5 (lima) hari. Namun demikian, dalam prakteknya ada yang melebihi 5 hari. Informasi tersebut diperoleh dari tenaga kesehatan Klinik Pratama Rawat Inap maupun dari pasien. Namun demikian, dalam Peraturan Menteri Kesehatan Republik Indonesia Nomor 028/ Menkes/Per/l/2011 Tentang Klinik tidak dijelaskan tentang ketentuan atau sanksi terhadap Klinik Pratama Rawat Inap yang memberikan pelayanan rawat inap lebih dari 5 (lima) hari.

Berdasarkan hasil wawancara dengan pemilik Klinik Pratama Rawat Inap tentang kegiatan pengawasan yang dilakukan oleh Dinas Kesehatan diperoleh informasi tidak ada temuan. Hal ini berbeda dengan informasi yang diberikan oleh Dinas Kesehatan maupun hasil dokumentasi berita acara pemeriksaan oleh Dinas Kesehatan.
Kondisi tersebut terjadi akibat kegiatan pengawasan oleh Dinas Kesehatan terhadap Klinik Pratama Rawat Inap tidak dilakukan secara menyeluruh dan kontinyu. Informasi yang diperoleh dari Dinas Kesehatan diketahui bahwa keterbatasan SDM baik menyangkut kualitas dan kuantitas menyebabkan kegiatan pengawasan terhadap Klinik Pratama Rawat Inap tidak dapat berjalan dengan baik.

Peraturan daerah yang mengatur tentang kegiatan pelayanan kesehatan oleh Klinik Pratama Rawat Inap sampai saat ini di Kabupaten Cilacap juga belum ada. Hal ini dapat disebabkan karena dalam Undangundang Kesehatan tidak disebutkan tentang Klinik. Peraturan Daerah menurut Prakoso merupakan produk pemerintah daerah yang bertujuan untuk mengatur hidup bersama, melindungi hak dan kewajiban masyarakat serta menjaga keselamatan dan tata tertib masyarakat di daerah yang bersangkutan. Pemahaman tersebut maka selayaknya setiap keputusan penting mengenai pengaturan dan pengurusan rumah tangga daerah harus selalu mengikutsertakan rakyat dengan melalui wakil-wakilnya yang duduk di Badan Perwakilan Rakyat. ${ }^{4}$

Dilihat dari konteks bekerjanya hukum Menurut L. Friedman, dalam hal ini adalah Permenkes. No. 028/Menkes/Per/l/2011 Tentang Klinik, maka faktor struktur, substansi dan kultur secara keseluruhan menjadi faktor yang menyebabkan penyelenggaraan pelayanan kesehatan oleh Klinik Pratama Rawat Inap belum dapat berjalan seperti apa yang seharusnya yang tercantum pada Permenkes. No. 028/Menkes/Per/l/2011 Tentang Klinik

Dilihat dari faktor struktur, fasilitas yang digunakan untuk menjamin agar pelayanan kesehatan oleh Klinik Pratama Rawat Inap dapat berjalan dengan baik belum ter-

Prakoso, Joko. 1985. Proses Pembuatan Peraturan Daerah dan Beberapa Usaha Penyempurnaannya, Jakarta : Ghalia Indonesia. HIm 45 
55 Jurnal Idea Hukum

Vol. 1 No. 1 Edisi Maret 2015

Magister Hukum Fakultas Hukum Universitas Jenderal Soedirman

sedia cukup. Keberadaan Dinas Kesehatan yang bertanggungjawab dalam melakukan pengawasan terkendala dengan kurangnya SDM baik secara kualitas maupun kuantitas. Kondisi tersebut menyebabkan kegiatan pengawasan tidak optimal. Faktor substansi, istilah klinik hanya ditemui pada Peraturan Menteri Kesehatan Republik Indonesia Nomor 028/Menkes/Per///2011 Tentang Klinik. Istilah Klinik tidak ditemui di undang-undang kesehatan maupun peraturan perundangundangan lainnya termasuk belum adanya peraturan daerah yang mengatur tentang Klinik. Peraturan Menteri Kesehatan Republik Indonesia Nomor 028/Menkes/Per/ I/2011 Tentang Klinik juga belum ada petunjuk pelaksanaan dan petunjuk teknisnya. Jika dilihat dari faktor kultural adalah karena lemahnya pemahaman masyarakat tentang pelayanan kesehatan yang standar baik dilihat dari sarana prasarana maupun tenaga kesehatan juga masih kurang. Warga masyarakat yang menggunakan jasa pelayanan kesehatan lebih dititikberatkan pada faktor kedekatan fasilitas kesehatan. Masyarakat menganggap seluruh fasilitas pelayanan kesehatan termasuk klinik dapat memberikan pelayanan kesehatan yang sama.

Berdasarkan pada hasil penelitian dari hasil wawancara, observasi dan dokumentasi hasil pengawasan Dinas Kesehatan Kabupaten Cilacap dapat dides-kripsikan beberapa pelanggaran terhadap Permenkes $\mathrm{RI}$ Nomor 028/Menkes/Per/l/2011 Tentang Klinik, pada Klinik Pratama Rawat Inap sebagai berikut: 1) Dokter hanya berada di Klinik Pratama Rawat Inap jika sedang melakukan praktik (ada klinik yang hanya ada satu dokter; 2) Pengelola ruang farmasi bukan seorang apoteker dan pelaksana bukan seorang tenaga teknik kefarmasian; 3) Penggunaan alat radiologi tanpa surat izin ; 4) Belum adanya SPO yang menjadi pedoman dalam memberikan tindakan medis maupun non medis. 5) Bangunan Klinik Pratama Rawat Inap yang masih bergabung dengan tempat tinggal pemilik; 6) Belum mempekerjakan tenaga apoteker sebagai pengelola atau penanggung jawab kefarmasian; 7) Belum adanya SPO yang menjadi pedoman dalam memberikan tindakan medis maupun non medis; 8) Pelayanan rawat inap melebihi batas maksimal rawat inap yaitu 5 (lima) hari; 9) Izin dikeluarkan oleh kepala Dinas Kesehatan Kabupaten Cilacap.

Adapun faktor-faktor yang menyebabkan terjadinya pelanggaran tersebut antara lain: 1) Jarak tempuh dokter antara domisili dan klinik tempat bekerja relatif jauh ( lebih dari 1 jam); 2) Ketidaktahuan tentang peraturan perundang-undangan bidang kesehatan; 3) Keterbatasan SDM; 4) Kurangnya pembinaan dan pengawasan oleh instansi yang berwenang; 5) Sanksi hanya berupa teguran, belum ada pencabutan izin usaha; 6) Belum adanya peraturan daerah yang mengatur tentang klinik; 7) Sanksi hanya berupa teguran, belum ada pencabutan izin; 8) Ketidaktahuan masyarakat terhadap pelayanan kesehatan di klinik; 9) Kurangnya pemahaman SDM Dinas Kesehatan tentang peraturan perundang-undangan bidang kesehatan.

Beberapa pelanggaran oleh Klinik Pratama Rawat Inap dalam penyelenggaraan pelayanan kesehatan sebagaimana diatur dalam Permenkes RI Nomor 028/Menkes/Per/l/2011 Tentang Klinik. Berdasarkan pada hasil wawancara dengan Dinas Kesehatan Kabupaten Cilacap diketahui bahwa sanksi yang diterapkan pada Klinik Pratama Rawat Inap bersifat administratif baik dengan teguran lisan maupun tertulis. Hal ini terkait dengan kewenangan Dinas Kesehatan yang hanya bersifat administratif.

Permenkes RI Nomor 028/Menkes/ Per///2011 Tentang Klinik juga tidak dijelaskan tentang sanksi lain selain sanksi administrasi. Selain itu juga tidak ada penjelasan lebih lanjut tentang sanksi administrasi tersebut. Menurut van Wijk bahwa yang dimaksud dengan sanksi administrasi ialah 
sarana-sarana kekuatan menurut hukum publik yang dapat diterapkan oleh badan atau jabatan tata usaha negara sebagal reaksi terhadap mereka yang tidak mentaati normanorma hukum tata usaha negara. ${ }^{5}$

Tidak adanya ketentuan lebih lanjut yang mengatur tentang sanksi yang administrasi dalam Permenkes RI No. 028/Menkes/ Per///2011 Tentang Klinik menyebabkan fungsi pengawasan yang dilakukan oleh Dinas Kesehatan untuk menjamin pelayanan kesehatan yang bermutu di Klinik Pratama Rawat Inap tidak dapat berjalan dengan optimal. Kondisi tersebut juga menyebabkan Dinas Kesehatan atau petugas yang berwenang melakukan pengawasan memberikan interpretasi yang berbeda-beda dalam penerapan sanksi tersebut.

Berdasarkan hasil temuan Dinas Kesehatan dalam pemeriksaan terhadap Klinik Pratama Rawat Inap antara lain adalah masalah belum adanya SPO dan ada klinik yang belum memiliki apoteker sebagai pengelola/ penanggungjawab kefarmasian pada Klinik Pratama Rawat Inap. Terkait dengan masalah SPO, dalam Peraturan Menteri Pendayagunaan Aparatur Negara Dan Reformasi Birokrasi Republik Indonesia Nomor 35 Tahun 2012 Tentang Pedoman Penyusunan Standar Operasional Prosedur Administrasi Pemerintahan disebutkan bahwa Standar Operasional Prosedur adalah serangkaian instruksi tertulis yang dibakukan mengenai berbagai proses penyelenggaraan aktivitas organisasi, bagaimana dan kapan harus dilakukan, dimana dan oleh siapa dilakukan.

Standar Prosedur Operasional, selanjutnya disingkat SPO menurut permenkes 1438/Menkes/Per/IX/2010 adalah suatu perangkat instrukti/langkah-langkah yang dibakukan untuk menyelesaikan proses kerja rutin tertentu, atau langkah yang benar dan ter-

Indroharto, 1994. Usaha Memahami UndangUndang Tentang Peradilan Tata Usaha Negara. hIm 238. baik berdasarkan konsensus bersama dalam melaksanakan berbagai kegiatan dan fungsi pelayanan yang dibuat oleh fasilitas pelayanan kesehatan berdasarkan standar profesi. Pimpinan fasilitas pelayanan kesehatan wajib memprakarsai penyusunan Standar Prosedur Operasional sesuai dengan jenis dan strata fasilitas pelayanan kesehatan yang dipimpinnya. SPO harus dijadikan panduan bagi seluruh tenaga kesehatan di fasilitas pelayanan kesehatan dalam melaksanakan kesehatan.

Belum adanya SPO di Klinik Pratama Rawat Inap menunjukkan setiap tindakan medis maupun non medis yang diberikan pada pasien tergantung pada tenaga kesehatan yang menangani dan memungkinkan pasien mendapatkan pelayanan yang berbeda pada jenis tindakan yang sama. Dinas kesehatan hanya dapat memberikan sanksi dengan memberikan saran agar melengkapi baik secara lisan maupun tertulis.

Ketentuan yang diatur dalam Pasal 29 Permenkes RI Nomor 028/Menkes/Per/l/2011 Tentang Klinik sebagai berikut:

(1) Dalam rangka pembinaan dan pengawasan, pemerintah dan pemerintah daerah sesuai dengan kewenangan masing-masing dapat mengambil tindakan administratif.

(2) Tindakan administratif sebagaimana dimaksud pada ayat (1) dilakukan meIalui: a) teguran lisan; b) teguran tertulis; atau c) pencabutan Izin.

Ketentuan tentang teguran lisan, tertulis maupun pencabutan izin tidak ada penjelasan ataupun ketentuan yang mengatur tentang persyaratan dari setiap sanksi administrasi tersebut. Hal ini menyebabkan instansi yang berwenang memberikan sanksi hanya berani memberikan sanksi berupa teguran lisan dan teguran tertulis saja terhadap temuan hasil pemeriksaan.

Faktor-faktor non hukum yang dapat mem-pengaruhi penegakan hokum menurut 
57 Jurnal Idea Hukum

Vol. 1 No. 1 Edisi Maret 2015

Magister Hukum Fakultas Hukum Universitas Jenderal Soedirman

Soer-jono Soekanto ${ }^{6}$ antara lain: (1) Substansi hukum, yaitu produk hukum, kaidah-kaidah yang terdapat di dalam aturan hukum; (2) Penegakan hukum (law enforcement sys-tem; (3) Sarana dan fasilitas, yaitu lem baga-lembaga yang mendukung pene-gakan hukum; (4) Faktor masyarakat, me-nyangkut status sosial dan individu di mas-yarakat; (5) Faktor budaya.

Sanksi yang diberikan oleh pemerintah berupa sanksi administratif, sejatinya sangat ringan dan berpotensi tidak menimbulkan efek jera bagi Klinik Pratama rawat Inap untuk melakukan pelanggaran yang serupa. Oleh karena itu, pemerintah yang berwenang untuk menegakkan hukum, hendaknya meningkatkan pengawasan dengan ketat terhadap proses penyelenggaraan pelayanan kesehatan yang diberikan oleh Klinik Pratama rawat Inap, agar masyarakat sebagai receiver atau penerima layanan kesehatan tidak dirugikan. Sehingga Klinik Pratama rawat Inap sebagai institusi yang memberikan pelayanan kesehatan benar-benar menjalankan fungsinya sebagai tempat yang digunakan untuk menyelenggarakan upaya pelayanan kesehatan, baik promotif, preventif, kuratif maupun rehabilitatif.

\section{Penutup \\ Simpulan}

Pelayanan kesehatan yang diselenggarakan oleh Klinik Pratama Rawat Inap belum sepenuhnya sesuai dengan yang diatur dalam Permenkes RI Nomor 028/Menkes/ Per/l/2011 tentang Klinik. Beberapa bentuk pelanggaran terhadap Permenkes RI Nomor 028/Menkes/Per/l/2011 tentang Klinik meliputi: (1) Belum tersedianya dokter yang selalu berada di Klinik Pratama Rawat Inap selama 24 jam; (2) Adanya klinik yang menggunakan alat radiologi tanpa surat Izin; (3) Belum seluruh Klinik Pratama Rawat Inap

6 Soerjono Soekanto, 1983, Faktor-Faktor yang Mempengaruhi Penegakkan Hukum, Jakarta, Raja Grafindo Persada, hlm 21 mempekerjakan tenaga apoteker sebagai penanggung jawab ruang farmasi (kefarmasian); (3) Belum tersedianya Standar Prosedur Operasional (SPO) tindakan medis maupun non medis; (4) Pelayanan rawat inap melebihi batas maksimal rawat inap yaitu 5 (lima) hari; (5) Ada Klinik Pratama Rawat Inap yang belum memiliki izin sudah beroperasional; (6) Izin Klinik Pratama Rawat Inap dikeluarkan oleh Kepala Dinas Keseha$\tan$

Faktor yang menyebabkan terjadinya pelanggaran terhadap Permenkes RI Nomor 028/Menkes/Per///2011 tentang Klinik diantaranya: (1) Keterbatasan SDM (dokter) yang domisili berdekatan dengan Klinik Pratama Rawat Inap; (2) Ketidak tahuan pengelola Klinik Pratama Rawat Inap tentang perizinan radiologi; (3) Perkembangan fasilitas kesehatan di Kabupaten Cilacap tidak seimbang dengan jumlah apoteker yang ada; (4) Pembinaan dan pengawasan oleh Dinas Kesehatan yang tidak berjalan dengan baik; (5) Peraturan perundang-undangan tidak disertai petunjuk pelaksanaan termasuk tentang kriteria sanksi; (6) Pemahaman masyarakat yang kurang tentang hak dan kewajiban untuk memperoleh pelayanan kesehatan yang baik; (7) Tidak dilakukannya evaluasi terhadap perizinan yang telah dikeluarkan; (8) Kurangnya SDM Dinas Kesehatan Kabupaten Cilacap bidang pelayanan kesehatan dan kefarmasian baik secara kwantitas maupun kwalitas; (9) Pemerintah Daerah Kabupaten Cilacap belum membuat peraturan daerah yang mengatur tentang klinik.

Penerapan sanksi terhadap Klinik Pratama Rawat Inap di Kabupaten Cilacap yang memberikan pelayanan kesehatan yang melakukan pelanggaran Permenkes RI Nomor 028/Menkes/Per///2011 Tentang Klinik hanya berupa teguran lisan maupun tertulis.

\section{Saran}

Permenkes RI Nomor 028/Menkes/ Per/l/2011 tentang Klinik perlu disertai de- 
ngan petunjuk pelaksanaanya terutama dalam hal sanksi, yaitu diberikan kriteria penjatuhan sanksi terhadap setiap pelanggaran.

\section{Daftar Pustaka}

\section{Buku}

Angkasa. 1993. Prisonisasi dan Permasalahannya terhadap Pembinaan Narapidana. Tesis. Semarang: Universitas Diponegoro;

Hermien Hadiati Koeswadji, 1998, Hukum Kedokteran, (Studi Tentang Hubungan Hukum Dalam Mana Dokter Sebagai Salah Satu Pihak), Bandung: Citra Aditya Bakti;

Indroharto, 1994. Usaha Memahami Undang-Undang Tentang Peradilan Tata Usaha Negara;

Peters, A.A.G dan Koesriani S, 2000. Hukum dan Perkembangan Sosial, Buku III, Jakarta: Pustaka Sinar Harapan;

Moleong, J. Lexy, 2000, Metodologi Penelitian Kualitatif, Bandung: Remaja Rosdakarya;

Prakoso, Joko. 1985. Proses Pembuatan Peraturan Daerah dan Beberapa Usaha Penyempurnaannya, Jakarta: Ghalia Indonesia;

Soemitro Ronny Hanitijo.1990. Metode Penelitian Hukum dan Jurimetri. Jakarta, Ghalia Indonesia;

Soekanto, Soerjono. 1983. Faktor-Faktor yang Mempengaruhi Penegakkan Hukum. Jakarta: Raja Grafindo Persada

\section{Peraturan Perundang-Undangan}

Undang-undang Nomor 10 Tahun 2004 tentang Pembentukan Peraturan Perundang-undangan;

Undang-Undang Republik Indonesia Nomor 29 tahun 2004 tentang praktik kedokteran;

Undang-Undang Republik Indonesia Nomor 36 tahun 2009 tentang Kesehatan;

Peraturan Menteri Kesehatan Republik Indonesia Nomor 028/Menkes/Per/l/ 2011 Tentang Klinik;

Peraturan Pemerintah Republik Indonesia Nomor 51 tahun 2009 Tentang Pekerjaan Kefarmasian. 